\title{
Intertextualidade no Lento (Assai) da Sinfonia n. 8 de Heitor Villa-Lobos
}

Intertextuality in the Lento (Assai) from Villa-Lobos' Symphony no.8

Adailton Sergio Pupia Departamento de Artes (UFPR) - adailtonpupia@yahoo.com.br 


\section{Resumo}

Este texto consiste na análise dos aspectos intertextuais presentes no Lento (Assai) da Sinfonia n. 8 de Heitor Villa-Lobos (1887-1959), composta em 1950. É observado de que forma essas relações intertextuais incidem, apresentando as influências musicais exercidas no compositor, compreendendo o contexto em que o mesmo estava inserido, observando com quais compositores Villa-Lobos dialogava e de que forma isso ocorria. O fenômeno intertextual na música é abordado através da análise tradicional conexa com conceitos intertextuais, apresentados em categorias. Estas categorias englobam elementos gestuais, motívicos e estilizações. Os elementos relacionados às estilizações, em especial da música popular brasileira, serão discutidos através das tópicas musicais.

Palavras-chave: Intertextualidade na música. Sinfonias. Análise musical. Heitor Villa-Lobos.

\section{Abstract}

This text consists of the analysis of intertextual aspects present in the Lento (Assai) of Symphony n. 8 by Heitor Villa-Lobos (1887-1959), composed in 1950. A discussion about the effect of intertextual relations is presented, including the composer's musical influences, contexts, other composers with whom Villa-Lobos converses, and the way in which this happens. The intertextual phenomenon in music is approached through traditional analysis related to intertextual concepts, presented in categories. These categories include gestural, motivic and stylized. The elements related to stylization, especially in regards to Brazilian popular music, will be discussed through musical topics.

Keywords: Intertextuality in music; Symphonies; Musical analysis; Heitor Villa-Lobos. 


\section{Introdução}

Heitor Villa-Lobos desenvolveu suas obras utilizando elementos da música tradicional europeia do final do século XIX, agregados à música popular brasileira e folclórica. Assim como os grandes compositores de sua geração, Villa-Lobos assimilou as técnicas herdadas do romantismo por meio do estudo acadêmico de formas musicais, contraponto e harmonia, instituído nos conservatórios e adotado como modelo no Brasil (SALLES, 2009, p. 19). Mesmo Villa-Lobos não admitindo intertextos em sua música - como afirmava: "Logo que sinto a influência de alguém, me sacudo todo e salto fora" (KIEFER, 1986, p. 34) -, muitos pesquisadores, como Norton Dudeque, Paulo de Tarso Salles, Acácio Tadeu Piedade e Gil Jardim, apontam o diálogo do compositor com obras de compositores precursores e contemporâneos, como a marcante presença de Claude Debussy, Igor Stravinsky, Richard Wagner, Johann Sebastian Bach, Darius Milhaud, entre outros.

Neste presente trabalho apresento algumas discussões analíticas referentes ao segundo movimento da Sinfonia n. 8 (1950) de Heitor Villa-Lobos. Por meio da intertextualidade e das tópicas musicais, serão observados elementos gestuais, motívicos e estilizações que dialogam com obras de compositores precursores e contemporâneos a Villa-Lobos.

As Sinfonias foram escritas em duas fases da vida do compositor, sendo que as quatro primeiras foram compostas no período de 1916 até 1919. Depois de 25 anos, Villa-Lobos retoma o ciclo compondo mais sete sinfonias no período de 1944 a 1957. Construídas na forma clássica em quatro movimentos, as Sinfonias destacam-se principalmente pela orquestração ${ }^{1}$. Suas primeiras sinfonias foram baseadas na estética do compositor francês Vincent d'Indy, que são apresentadas em seu livro Cours de Composition Musicale ${ }^{2}$, adotado pelos professores do Instituto Nacional de Música, ligado diretamente à música de Richard Wagner (GUÉRIOS, 2003, p. 87).

Diferentemente do ciclo dos Choros ou das Bachianas Brasileiras, as doze ${ }^{3}$ Sinfonias são, de um modo geral, pouco nacionalistas, não havendo uma grande repercussão por parte do grande público nacional e estrangeiro (COLARUSSO, 2013). Isso não significa que elas sejam menos importantes dentro do repertório villalobiano. O próprio compositor orgulhava-se das suas sinfonias, considerando uma composição musical superior, como menciona em uma palestra proferida em Paris, em 1958.

O que é uma sinfonia, em meu ponto de vista, no ponto de vista de todas as pessoas que escrevem sinfonias? É uma música pela música. Música superior, música intelectual, não é música para ser assobiada por todo mundo. Bem, quando

\footnotetext{
1 Em uma entrevista, o compositor francês Olivier Messiaen demonstrou uma grande admiração por Villa-Lobos, citando o compositor brasileiro como dono de "uma orquestração maravilhosa" e cujos Choros foram o "ponto de partida de algumas explorações do timbre" (GOLÉA, 1960, p. 85 apud TAFFARELLO, 2010, p. 25).

2 Villa-Lobos teria ganhado uma cópia do livro do Dr. Leão Veloso, trazido da Europa, "ao qual Villa-Lobos atribuía tanta importância em sua formação e cujo o estudo aprofundado situava em 1914" (LAGO, 2010, p. 80).

3 A Quinta Sinfonia, composta em 1920, é dada como perdida. Intitulada "A Paz", essa sinfonia faz parte do ciclo das cinco sinfonias escritas ao estilo do compositor francês Vincent d'Indy.
} 
há uma sinfonia, se alguém tenta empregar efeitos especiais, de tipo exótico, folclore ou algo parecido, eu não acho correto chamá-la de sinfonia [...]. (GUÉRIOS, 2009, p. 167).

A Sinfonia n. 8 foi composta em 1950 no Rio de Janeiro, sendo dedicada ao crítico musical Olin Downes ${ }^{4}$. Dividida em quatro movimentos, foi estreada sob a regência de Villa-Lobos em 1955, pela Orquestra da Filadélfia no Carnegie Hall em Nova York. De rica instrumentação, a Sinfonia $n .8$ é dividida em quatro movimentos: Andante, Lento (Assai), Allegretto Scherzando e Allegro Giusto.

\section{Fundamentação teórica}

Consolidados na linguística, os primeiros estudos sobre influência e intertextualidade ocorreram na década de 1960, engajados pela búlgaro-francesa Júlia Kristeva e pelo estadunidense Harold Bloom, em 1973. Mikhail Bakhtin, teórico literário russo, foi o primeiro pensador a abordar o conceito de intertextos, denominando-o "dialogismo5". Bakhtin assinala que todo discurso se constitui perante o outro e não sobre si mesmo, sempre encontramos a voz do outro, pois é "o outro" que nos define, que nos completa (FREITAS, 2011, p. 29).

Segundo Kristeva, "todo texto se constrói como mosaico de citações, todo texto é absorção e transformação de outro texto. Em lugar da noção de intersubjetividade, instala-se a de intertextualidade, e a linguagem poética lê-se pelo menos como dupla" (KRISTEVA, 1974, p. 142).

No livro A Angústia da Influência, de 1973, o crítico literário estadunidense Harold Bloom motivou diversos músicos teóricos a adaptar e aplicar esta teoria derivada da linguística para a análise da linguagem musical. Neste livro, a história da poesia é traçada a partir da desleitura ${ }^{6}$ que os "poetas fortes" fazem da obra de seus precursores, sendo um processo de "correção criativa8". A desleitura é o jovem poeta fazendo o poeta precursor dizer o que este jovem poeta quer ou necessita ouvir. A desleitura não é uma falha ou uma interpretação inadequada, mas, sim, um processo de "correção criativa" (STRAUS, 1990, p. 14).

A teoria de Harold Bloom é complexa e difícil de sintetizar, pois Bloom utiliza uma série de referências, inclusive de origem esotérica. Straus condensa os quatro funda-

\footnotetext{
$4 \quad$ Olin Downes era engajado na descoberta e militância pela música de grandes compositores fora da Europa Central e dos Estados Unidos, como o finlandês Jean Sibelius e Heitor Villa-Lobos. Ele divulgou estes dois compositores nos Estados Unidos, ajudando a torná-los menos "exóticos" aos olhos e ouvidos do grande público.

5 Segundo Bakhtin, o "dialogismo" é o processo de interação entre textos que ocorre na polifonia, tanto na escrita como na leitura. 0 texto não é observado isoladamente, mas, sim, relacionado com outros discursos similares.

6 Desleitura é uma possível tradução do vocábulo original misprision ou misreading de Harold Bloom, os quais não possuem equivalentes diretos na língua portuguesa, particularmente misprision, que é uma construção do próprio Bloom. Esse termo é utilizado na tradução do livro $A$ Map of Misreading (1975) de Harold Bloom, traduzido por Thelma M. Nóbrega como Um Mapa da Desleitura (2003). Esse conceito remete ao modo como um poeta ajuda a formar outro, e como este outro desviou deliberadamente a sua leitura do primeiro poeta no sentido de servir aos seus próprios interesses. 0 que se tem é um quadro das relações intrapoéticas, ou aquilo que Bloom designa por misprision.

7 O poeta forte é o "poeta capaz de sobreviver ao conflito edipiano com a tradição, criando para si um lugar ao sol e mentir contra o tempo narrando a si mesmo como um início" (CASTRO, 2011, p. 9-10).

8 "A influência poética - quando envolve dois poetas fortes, autênticos - sempre se dá por uma leitura distorcida do poeta anterior, um ato de correção criativa que é na verdade e necessariamente uma interpretação distorcida" (BLO0M, 2002, p. 80)
} 
mentos da teoria da angústia da influência de Harold Bloom. O primeiro é a insuficiência de um poema sendo apresentado como um evento relacional, que contém impulsos a partir de uma variedade de fontes. Já o segundo refere-se à tradição poética e à história da poesia, onde ocorre uma luta entre poetas e seus antecessores. O terceiro aponta a batalha entre os poemas posteriores e seus precursores. Poetas posteriores intencionalmente interpretam mal os seus antecessores. E, por fim, a angústia da influência, que é um fenômeno universal na poesia e não é limitado a um único período histórico (STRAUS, 1990, p.12).

Segundo Bloom, a preocupação do poeta com sua individualidade vem da ansiedade de não haver espaço deixado por seus precursores, sendo impossível falar com sua própria voz poética. Sendo assim, a angústia torna-se algo com que os poetas atualmente lutam, ao invés de algo que eles recebem passivamente, e a poesia torna-se um campo de batalha psíquico onde poemas procuram reprimir ou excluir outros poemas (KORSYN, 1991, p. 7).

Bloom apresenta seis modos de desleitura do precursor. Esses seis modos de interpretações da influência são chamados de proporções revisionárias ${ }^{9}$ mais ou menos arbitrárias que regem a influência entre autores. Estas proporções são também tropos de linguagem ${ }^{10}$, mostrando que seu aspecto estrutural é fortemente mutante e, portanto, aberto aos mais variados tipos de transformação (KORSYN, 1991, p. 10).

Bloom (2002) apresenta uma sinopse das seis proporções revisionárias, sendo Clinamen, Tessera, Kenosis, Daemonização, Askesis e Apophrades. Tomo como exemplo a descrição da Tessera: sendo a completude e a antítese. Na Tessera, "o poeta 'completa' antiteticamente seu precursor, lendo o poema-pai de modo a reter seus termos, mas usando-os em outro sentido, como se o precursor não houvesse ido longe o bastante" (BLOOM, 2002, p. 64).

Em Paródia, Paráfrase \& Cia, Affonso Romano de Sant'Anna oferece quatro categorias intertextuais, sendo: apropriação, paródia, estilização e paráfrase, para "esclarecer o enigma do que é 'literário' e a entender a formação da ideologia através da linguagem" (SANT'ANNA, 2003, p. 6). Nogueira assinala que, segundo Sant'Anna (2003), os "diversos graus de integração ou desvio de sentido ou estilo entre um texto e intertextos atuantes, resultantes do propósito da semelhança ou da diferença, distinguem quatro tipos de intertextualidade, que se situam entre o hibridismo e a fusão estilística" (NOGUEIRA, 2003, p. 3).

Muitos destes conceitos trazidos da linguística foram aplicados à música a partir da década de 1980, sendo alguns derivados dos estudos de Bloom, como veremos a seguir.

No dicionário Grove Music Online, J. Peter Burkholder apresenta uma definição sobre intertextualidade na música.

\footnotetext{
$9 \quad$ O termo proporções revisionárias será utilizado neste trabalho como tradução do termo revisionary ratios. A tradução do livro A Angústia da Influência, de Harold Bloom, traz a tradução adotada neste trabalho (Marcos Santarrita, 2002).

10 Tropos podem ser entendidos como aquele elemento que desvia significados ou gera efeitos especiais no rearranjo das palavras (CASTRO, 2011, p. 7)
} 
Aplicado à música desde os anos 1980, é um termo mais amplo do que um empréstimo, que normalmente concentra-se no uso de uma peça tendo um ou mais elementos tomados de outro. Assim a intertextualidade abrange a utilização de um estilo geral ou linguagem, bem como de uma melodia emprestada. Além disso, enquanto o empréstimo é uma relação mono direcional em que uma peça toma emprestada de outra, a intertextualidade engloba relações mútuas, como quando duas peças desenham a mesma convenção, mas nenhum dos compositores estava ciente da outra peça ${ }^{11}$. (BURKHOLDER, tradução do autor).

A relação intertextual é abrangente e nem sempre consciente, envolve não apenas a desleitura entre poetas, como também a desleitura do leitor. Bloom aponta que "qualquer poema é um interpoema, e qualquer leitura de um poema é uma interleitura. $O$ poema não está sendo escrito, mas sim reescrito... ${ }^{12 " ~(B L O O M, ~ 1976, ~ p . ~} 3$ apud STRAUS, 1990, p. 13).

As teorias sobre influência de Harold Bloom fundamentaram estudos relacionados à música de Joseph N. Straus (1990) e Kevin Korsyn (1991). Contudo, um dos primeiros estudos sobre a influência na música é o artigo intitulado "Influence: Plagiarism and Inspiration", de Charles Rosen, publicado em 1980. O artigo traz uma análise da influência exercida por Frédéric Chopin na obra de Johannes Brahms, especificamente no Scherzo Op.4 de Brahms, que o autor identifica como sendo derivado diretamente do Scherzo Op. 31 de Chopin. Para Rosen, a influência é um processo benéfico, um modelo que inspira compositores a darem o seu melhor e exporem sua personalidade na obra.

Este mesmo trecho musical é abordado posteriormente por Kevin Korsyn no artigo intitulado "Toward a New Poetics of Musical Influence", de 1991. No artigo, Korsyn observa uma possível interpretação errônea na comparação de Rosen entre os Scherzos, sugerindo que o Scherzo Op.4 de Brahms seria interpretado com maior precisão sendo uma derivação da Waltz Op.64, n. 2 de Chopin.

Korsyn apresenta de forma diferenciada a relação de influência entre Chopin e Brahms, através da associação das proporções revisionárias, dos tropos retóricos e das defesas psíquicas, elementos derivados diretamente das teorias de Bloom. Korsyn, auxiliado por ferramentas analíticas, como a análise schenkeriana, aplica o modelo apresentado por Bloom para verificar as relações entre a Romanze, Op. 118, n. 5 de Brahms e a Berceuse, Op. 57 de Chopin. Segundo Korsyn, "não é meramente suficiente acumular dados através da observação de similaridades entre peças; nós necessitamos de um modelo para explicar quais similaridades são significantes, [...]. O modelo nos diz onde olhar, o que observar'13, [...]" (KORSYN, 1991, p. 5).

Inspirado nas teorias de Harold Bloom, Joseph Nathan Straus, em seu livro Re-

\footnotetext{
11 "Applied to music since the 1980s, it is a broader term than borrowing, which typically focusses on the use in one piece of one or more elements taken from another. Thus intertextuality embraces the use of a general style or language as well as of a borrowed melody. Moreover, while borrowing is a monodirectional relationship in which one piece borrows from another, intertextuality encompasses mutual relationships, as when two pieces draw on the same convention but neither composer was aware of the other piece" (BURKHOLDER).

12 "Any poem is an inter-poem, and any reading of a poem is an inter-reading. A poem is not writing, but rewriting [...]" (BLOOM, 1976, p. 3 apud STRAUS, 1990, p. 13).

13 "[...] not enough merely to accumulate data by observing similarities among pieces; we need models to explain which similarities are significant, [...]. Models tell us where to look, what to observe, [...] (KORSYN, 1991, p. 5).
} 
making the Past: Musical Modernism and the Influence of the Tonal Tradition, de 1990, discute os caminhos trilhados por Arnold Schoenberg, Anton Webern, Alban Berg, Igor Stravinsky e Béla Bartók, relacionando a transformação da música tonal do passado em suas próprias linguagens modernistas. Straus aponta que "as obras musicais mais importantes e características da primeira metade do século incorporam e reinterpretam elementos da música antiga ${ }^{14 "}$ (STRAUS, 1990, p. 2). Straus assinala que este processo de incorporação e reinterpretação, mais do que elementos de estilos ou de estruturas, define a principal corrente do modernismo musical (STRAUS, 1990, p. 2).

Focado no repertório do século XX, Straus (1990) apresenta três modelos intertextuais: a "influência como imaturidade", a "influência como generosidade", ambas baseadas nas teorias de T. S. Eliot ${ }^{15}$, e a "influência como ansiedade", baseada na teoria de Harold Bloom.

De acordo com Straus, a suscetibilidade à influência é comumente vista como "influência como imaturidade", onde o jovem compositor frequentemente utiliza elementos do estilo ou da estrutura musical inspirados em seu professor ou em outro compositor antecessor. Este tipo de influência é considerado uma indicação de fraqueza artística, de um trabalho secundário (STRAUS, 1990, p. 9). Straus aponta a ocorrência deste tipo de influência na Sinfonia em Mi= de Igor Stravinsky, o compositor sendo ali diretamente influenciado por Rimsky-Korsakov, seu professor na época em que a obra foi composta (no período de 1905 a 1907).

O conceito de "influência como generosidade" foi desenvolvido principalmente por T. S. Eliot, apontando que a suscetibilidade à influência não é um sinal de incapacidade, mas, sim, de valor, onde o principal da tradição é assimilado: “[...] mesmo em obras que parecem mais individuais, os bons artistas irão demonstrar consciência do passado16" (STRAUS, 1990, p. 10). Straus aponta que, para Eliot, as obras do passado têm um impacto decisivo em qualquer trabalho posterior: "Na visão de Eliot, a verdadeira criatividade artística envolve autonegação, uma vontade de se abrir e de se subordinar à influência do passado"17" (STRAUS, 1990, p. 10).

$\mathrm{Na}$ "influência como ansiedade", derivada da teoria de Harold Bloom (1973), a relação entre o poeta jovem e seus predecessores não é generosa ou benéfica, mas de ansiedade, raiva e repressão. Straus assinala que a teoria da "influência como ansiedade" de Bloom é relativamente recente e exclusivamente frutífera para entender a música do século XX, possuindo uma "rica interação de elementos contrastantes e conflitante ${ }^{18}$ " (STRAUS, 1990, p. 12).

\footnotetext{
14 "The most important and characteristic musical works of the first half of this century incorporate and reinterpret elements of earlier music" (STRAUS, 1990, p. 2)

15 Poeta modernista, dramaturgo e crítico literário inglês nascido nos Estados Unidos. Recebeu o Prêmio Nobel de Literatura de 1948.

16 "Even in works that seem most individual, good artists will demonstrate consciousness of the past" (STRAUS, 1990, p. 10).

17 "In Eliot's view, true artistic creativity involves self-denial, a willingness to open and subordinate oneself to the influence of the past" (STRAUS, 1990, p. 10)

18 "[...] rich interplay of contrasting and conflicting elements" (STRAUS, 1990, p. 12).
} 
Inspirado no modelo de Bloom, Straus apresenta oito estratégias (categorias) composicionais. Igualadas às proporções revisionárias, Straus utiliza estas estratégias em obras do século XX, observando os elementos intertextuais ocorrentes. Essas estratégias são nomeadas motivização, generalização, marginalização, centralização, compressão, fragmentação, neutralização e simetrização. Straus oferece uma pequena descrição destas estratégias, como a categoria relacionada ao motivo, a motivização, onde "o conteúdo motívico de uma obra anterior é radicalmente intensificado"19" (STRAUS, 1990, p. 17).

Michael Leslie Klein, em seu livro Intertextuality in Western Art Music, de 2005, apresenta um aprofundamento na revisão de literatura e aponta novas direções para a distinção da influência e da intertextualidade, "onde a primeira implica na intenção ou colocação histórica da obra em seu tempo ou origem, e a última implica em uma noção mais geral de cruzamento de textos que podem envolver a reversão histórica" (KLEIN, 2005, p. 4).

Martha M. Hyde, em seu artigo "Neoclassic and Anachronistic Impulses in Twentieth-Century Music", de 1996, apresenta quatro extensas análises destinadas a ilustrar quatro impulsos distintos ou estratégias pelas quais compositores do início do século XX criaram suas obras modernas que envolvem ou reconstroem o passado, sem sacrificar a sua própria integridade na história dos estilos. Através da remodelagem dos estudos literários de Thomas Greene, Hyde adaptou vários conceitos para a linguagem musical, apresentando quatro tipos de imitação ou "anacronismos metamórficos", sendo eles a imitação reverencial, eclética, heurística e dialética.

Baseado nos estudos de Straus (1990), Lucas de Paulo Barbosa e Lúcia Silva Barrenechea (2003) propõem uma nomenclatura analítica que nos permite observar o fenômeno da influência entre as obras musicais. Os autores dispõem de sete categorias: entidades orgânicas elementares, extrato, idiomática, paráfrase, estilo, paródia e reinvenção.

Ilza Nogueira observa a relação intertextual em obras de compositores brasileiros contemporâneos, com o objetivo de "mostrar e avaliar motivações e propósitos diversos no uso da apropriação intelectual, tais como expressão ideológica e recurso estilístico" (NOGUEIRA, 2003, p. 2). Entre os compositores abordados estão José Alberto Kaplan, Lindembergue Cardoso, Wellington Gomes e a própria Ilza Nogueira. A compreensão da diversidade intertextual tem como referencial a teoria de Affonso Romano Sant'Anna em seu livro Paródia, Paráfrase \& Cia (2007). Os tipos (categorias) intertextuais apresentados por Sant'Anna (1985) são direcionados para a música por Nogueira, sendo eles apropriação, paródia, estilização e paráfrase. Nogueira descreve estes quatro elementos igualmente como apresentados por Sant'Anna (2007), a exemplo de apropriação, que é caracterizada como "uma técnica de articulação de textos alheios num contexto diverso, como numa colagem ou montagem. Desvinculados de seus contextos originais, tratados como material, os textos apropriados estão sujeitos a uma nova leitura" (NOGUEIRA, 2003, p. 4).

Rubén López Cano apresenta, através dos apontamentos do crítico literário e teórico francês Michel Riffaterre, a noção de intertextualidade não sendo referida exclusi- 
vamente com a relação de uma obra com obras anteriores, que poderiam servir como fonte de menção ou inspiração, mas sim a relação de uma obra anterior ou posterior com a detecção de um ouvinte competente, onde é estabelecido o parentesco entre os momentos de várias obras, situando redes de conexões na sua compreensão (CANO, 2007, p. 30-31). Cano aponta cinco tipos de intertextualidade: citação, paródia, transformação de um original, tópica e alusão.

O conceito da teoria das tópicas musicais foi apresentado por Leonard Ratner, em seu livro Classic Music: Expression, form, and style, de 1980. Ratner propõe uma explicação em grande escala das premissas estilísticas da música clássica por volta de 1770 a 1800, enfatizando a música de Joseph Haydn, Wolfgang Amadeus Mozart e Ludwig van Beethoven. Inúmeras referências aos compositores precursores também são realizadas, oferecendo um conjunto de critérios extraídos da análise musical e dos tratados teóricos do final do século XVIII. A música do início do século XVIII, através do contato com poesia, drama, entretenimento, religião, dança, cerimônia, música militar e de caça, desenvolveu um compêndio de figuras características, tornando-se um rico legado para os compositores clássicos. Essas figuras características são designadas por Ratner como tópicas, sendo equivalentes aos sujeitos para o discurso musical. As tópicas aparecem como tipos, ou figuras, e progressões dentro de uma peça, isto é, estilos. Segundo Ratner, a distinção entre tipos e estilos é flexível, "minuetos e marchas representam tipos completos de composição, mas também eles fornecem estilos para as outras peças" (RATNER, 1980, p. 9).

De acordo com Monelle, as tópicas musicais são mais do que meras etiquetas, são dependentes "de investigações da história social, literatura, cultura popular e ideologia, bem como música, [e] cada tópica deve levar a um longo estudo cultural20" (MONELLE, 2006, p. xi). Cano define a tópica musical como uma categoria intertextual, sendo constituída de elementos musicais que nos remetem a um gênero, estilo ou tipo de música, não fazendo referência a uma obra reconhecível, mas, sim, a elementos genéricos sem paternidade autoral específica (CANO, 2007, p. 34). Assinala ainda que as tópicas musicais permitem o desenrolar de estratégias analíticas mais eficazes para os estudos dos processos semióticos produzidos pela intertextualidade (CANO, 2005, p. 63).

As tópicas musicais, de acordo com Piedade, são figurações musicais que foram construídas através de complexos processos históricos e culturais de natureza regional, nacional e internacional. As tópicas são "mais do que clichês ou maneirismos, as tópicas são elementos estruturais (motivos, variações, texturas, ornamentos etc.) que portam significados e que constituem o texto musical" (PIEDADE, 2009, p. 127). Ainda segundo o autor, as tópicas são "estruturas convencionais e consensuais, lugares comuns dos discursos musicais, que estão fundadas em uma musicalidade específica e ali mantêm certa estabilidade histórica" (PIEDADE, 2015, p. 2). Piedade traz um compêndio de tópicas ocorrentes na música villalobiana.

20 "[...] must depend on investigations of social history, literature, popular culture, and ideology as well as music, each topic must lead to a lengthy cultural study" (MONELLE, 2006, p. xi). 


\section{Comentários analíticos}

As análises aqui apresentadas serão distribuídas em categorias intertextuais. Estas categorias são fundamentadas nos estudos de Straus (1990), Hyde (1996), Barbosa e Barrenechea (2003), Nogueira (2003) e Cano (2007). A música popular brasileira será investigada através das tópicas musicais, fundamentadas nos estudos de Piedade (2009).

Os procedimentos analíticos irão variar de acordo com o material a ser observado, utilizando ferramentas como a análise reducionista, motívica, comparativa, rítmica, formal, harmônica, dentre outras. Como já mencionado, a Sinfonia n. 8 é de rica instrumentação, conforme mostra a Fig. 1:

\begin{tabular}{|c|c|}
\hline 2 Piccolos & Tímpanos \\
\hline 2 Flautas & Tam-tam \\
\hline 2 Oboés, & Pratos \\
\hline Corne Inglês & Xilofone \\
\hline 2 Clarinetas $(\mathrm{B} \cong)$ & Celesta \\
\hline Clarinete Baixo & 2 Harpas \\
\hline 2 Fagotes & Piano \\
\hline Contra fagote & Primeiros Violinos \\
\hline 4 Trompas & Segundos Violinos \\
\hline 4 Trompetes $(\mathrm{B} \cong)$ & Violas \\
\hline 4 Trombones & Violoncelos \\
\hline Tuba & Contrabaixos \\
\hline
\end{tabular}

Fig. 1 - Instrumentação da Sinfonia n. 8 de Heitor Villa-Lobos

A estruturação formal de diversas obras de Villa-Lobos é construída como A-B-A1, muitas vezes com adição de introduções ou de pequenas alterações, como no Lento (Assai) da Sinfonia n. 8.

\begin{tabular}{|l|l|}
\hline Abertura (Lento Assai) & c. $1-2$ \\
\hline Parte A & c. $3-9$ \\
$1^{\text {o }}$ tema & c. $9-18$ \\
$1^{\text {o }}$ tema (pequenas variações) & \\
\hline Parte $\mathbf{B}$ & c. $19-26$ \\
$2^{\circ}$ tema & c. $27-31$ \\
$2^{\circ}$ tema (pequenas variações) & c. $32-34$ \\
Transição $^{\text {Parte } \mathbf{A}^{\mathbf{1}} \text { (reexposição) }}$ & c. $35-41$ \\
$1^{\text {o }}$ tema (pequenas variações) & c. $42-59$ \\
Transição & c. $60-62$ \\
Abertura &
\end{tabular}

Fig. 2 - Estrutura formal do segundo movimento, Lento (Assai) da Sinfonia n. 8 de Heitor Villa-Lobos 


\subsection{Relações Intertextuais Motívicas}

Nesta categoria intertextual são apresentadas as relações motívicas. Segundo Barbosa e Barrenechea, estes elementos intertextuais motívicos não devem ser entendidos como uma "mera similaridade intervalar entre células musicais [...]. Para que um intervalo adquira sentido musical, o mesmo deve estar carregado de intencionalidade, ou seja, ele está ali para provocar um efeito sonoro específico". Este tipo de intertextualidade descreve "as relações entre elementos musicais de proporções reduzidas", sendo que a sua utilização "descreverá a intertextualidade em que um elemento musical com proporções reduzidas é copiado e transportado para dentro de um outro contexto musical, sem que o mesmo perca sua identidade ou efeito sonoro" (BARBOSA e BARRENECHEA, 2003, p. 133).

Straus apresenta a relação intertextual do conteúdo motívico através da motivização, onde o "conteúdo motívico de uma obra anterior é radicalmente intensificado" (STRAUS, 1990, p. 17). Esta relação motívica ainda pode ser relacionada à imitação heurística, apresentada por Hyde (1996), onde a ligação com o passado é acentuada, ao invés de ser escondida, fazendo a afirmação de sua dependência a um modelo anterior, que nos obriga a reconhecer a disparidade, o anacronismo da conexão que está sendo estabelecida (HYDE, 1996, p. 2014).

Na seção A do Lento (Assai), alguns elementos fazem alusão ao Prelúdio da ópera Tristão e Isolda, de Richard Wagner. Sem dúvida Wagner exerceu grande influência na obra de Heitor Villa-Lobos e de diversos compositores do final do século XIX. Essa influência wagneriana ocorreu no Brasil através do filtro da música francesa, sob a "orientação de músicos como César Franck, Vincent d'Indy e Camille Saint-Säens, reconhecidos cultores do compositor alemão" (SALLES, 2004, p. 1). Segundo Salles, o maior empréstimo que Villa-Lobos fez de Wagner está no "campo da orquestração e na apresentação de pequenos fragmentos temáticos à maneira dos leitmotivs wagnerianos, presentes em vários de seus poemas sinfônicos" (SALLES, 2009, p. 24).

No Rio de Janeiro, a música de Wagner era bastante difundida por Francisco Braga $^{21}$, Leopoldo Miguéz ${ }^{22}$ e Alberto Nepomuceno ${ }^{23}$. Villa-Lobos desenvolveu-se neste ambiente musical em que a obra de Wagner era reverenciada. Como já mencionado, Villa-Lobos teve contato com o tratado de composição Cours de Composition Musicale de d'Indy, onde há várias referências a Tristão e Isolda e outras realizações de Wagner. ner, em 1896 viajou pela primeira vez para Viena, Dresden e Bayreuth, onde assistiu à encenação das óperas Der Ring des Nibelungen e Parsifal, de Wagner (GONTIJO, 2006, p. 23).

22 Miguéz chegou à Europa em 1882, ano da morte de Richard Wagner, o que lhe causou grande impacto. Quando retornou ao Brasil, em 1884, a sua militância pelos ideais estéticos de Wagner o levou a fundar juntamente com o escritor Coelho Neto e vários jovens intelectuais, além do compositor Alberto Nepomuceno, o Centro Artístico, que seria responsável pela propagação das ideias de Wagner no Brasil (CROWL, 2013, p. 7-8).

23 Em sua estada em Berlim, Nepomuceno esteve em contato com as inovações de Richard Wagner, sendo o primeiro compositor brasileiro a utilizar determinadas combinações musicais que caracterizavam os novos tempos. Em 1913, já no Brasil, regeu no Theatro Municipal do Rio de Janeiro trechos das óperas Die Meistersinger von Nürnberg, Der Fliegende Holländer, Tannhäuser, Die Walküre e Lohengrin no Festival Wagner. Crowl aponta que o ambiente musical carioca era bastante marcado pelo culto à música de Richard Wagner, influenciando de forma significativa Heitor Villa-Lobos (CROWL, 2013, p. 24) 
Villa-Lobos, assim como tantos compositores, não ficou imune às várias análises e discussões em torno das inovações harmônicas do Prelúdio dessa ópera, cujos acordes iniciais tornaram-se uma espécie de arquétipo harmônico (SALLES, 2009, p. 28).

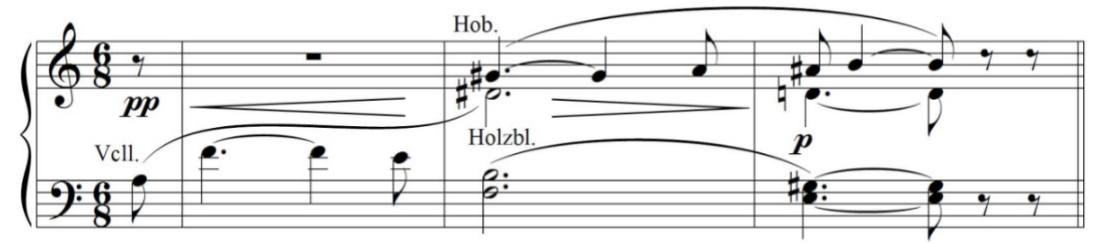

Fig. 3 - Redução dos compassos iniciais do Prelúdio da ópera Tristão e Isolda de Richard Wagner.

O motivo Tristão, apresentado na Fig. 4, é caracterizado pela sexta menor ascendente (notas Lá e Fá) com sua resolução cromática descendente (notas Mi, Ré\# e Ré ), recorrente em diversos momentos da ópera Tristão e Isolda.

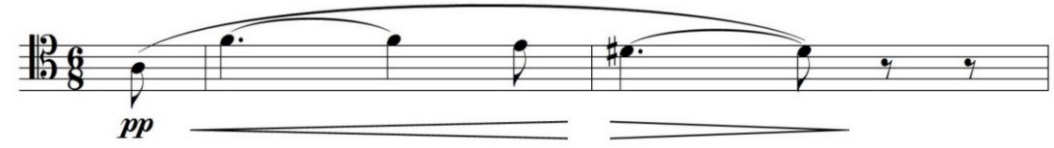

Fig. 4 - Motivo Tristão. Prelúdio da ópera Tristão e Isolda. Melodia do violoncelo. Compassos 1-2.

No Lento (Assai) da Sinfonia n. 8, ocorrem algumas alusões ao gestual deste motivo. Na seção A, nos compassos 2 ao 3, observamos o intervalo de 6a menor ascendente, realizado pela viola sem acompanhamento da orquestra. $O$ timbre, a orquestração e o intervalo inicial (notas Lá e Fá, idêntico ao motivo Tristão) corroboram essa associação, remetendo aos procedimentos iniciais do Prelúdio da ópera Tristão e Isolda.

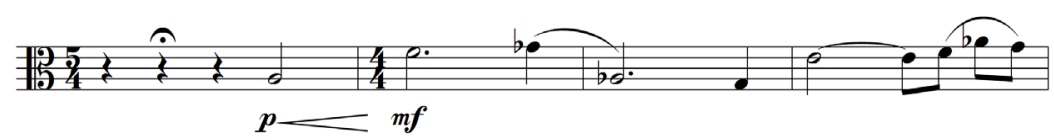

Fig. 5 - Gestual do motivo Tristão. Lento (Assai) da Sinfonia n. 8 de Heitor Villa-Lobos. Melodia da viola. Compassos 2-5.

Esse gestual é recorrente no compasso 10 (viola e corne inglês), compasso 11 (oboé), e na recapitulação, no compasso 35 (primeiros e segundos violinos), compasso 42 (corne inglês) e compasso 43 (flauta transversal). Em diversos momentos deste movimento ocorre a utilização deste gesto intervalar de 6a menor ascendente, porém apenas nestes excertos citados o motivo Tristão é caracterizado, seja pela instrumentação, orquestração ou textura.

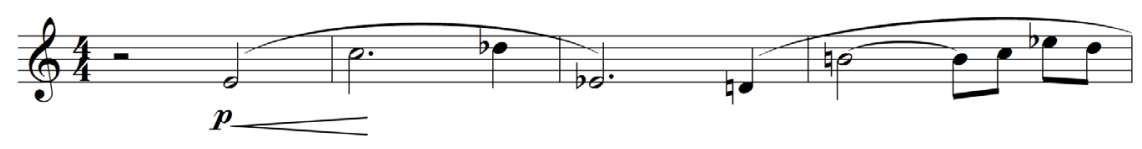

Fig. 6 - Gestual do motivo Tristão. Lento (Assai) da Sinfonia n. 8 de Heitor Villa-Lobos. Melodia do corne inglês. Compassos 10-13. 


\subsection{Relações Intertextuais de Estilo}

Esta categoria é bastante abrangente, podendo englobar vários elementos. Estes elementos podem estar associados ao estilo composicional de um determinado compositor, a uma obra musical específica, a um período musical específico, a uma forma musical, a uma configuração específica de estilo musical, dentre outros aspectos.

Segundo Barbosa e Barrenechea, o estilo é empregado para "demonstrar o tratamento pessoal dado aos recursos e técnicas compositivas. A influência no nível estilístico significaria que, em uma obra, o compositor se apropriou da maneira como seu antecessor tratou os recursos e técnicas compositivas na elaboração do discurso musical" (BARBOSA e BARRENECHEA, 2003, p. 134).

Ilza Nogueira trata a estilização como um processo criativo, inovando, porém sem subverter o conteúdo da obra original.

A estilização anda na mesma direção do objeto estilizado, pois se mantém fiel ao paradigma inicial, sem trair a organização ideológica do sistema, como ocorreria na paródia. Inovando sem subverter, perverter ou inverter o sentido, possibilita a introdução de um tratamento pessoal no discurso, uma reforma, sem modificação essencial da estrutura. Há, portanto, uma atitude criativa. (NOGUEIRA, 2003, p. 4).

\subsubsection{Finalizações Varèsianas}

Segundo Salles, Villa-Lobos apresenta duas fórmulas básicas de finalizações ${ }^{24}$, "que encerram muitas de suas obras e/ou movimentos, as quais designaremos como cadências do tipo 'wagneriana' e 'varèsianas'"' (SALLES, 2009, p. 144).

A finalização "varèsiana" empregada por Villa-Lobos possuiu uma afinidade com os procedimentos utilizados por Edgard Varèse. Este fechamento seccional é caracterizado pela presença de um acorde final "marcado pelas ressonâncias e pelos sons resultantes de diversas dissonâncias agregadas [...], como em Intégrales, para 11 sopros e percussão (1925)" (SALLES, 2009, p. 145).

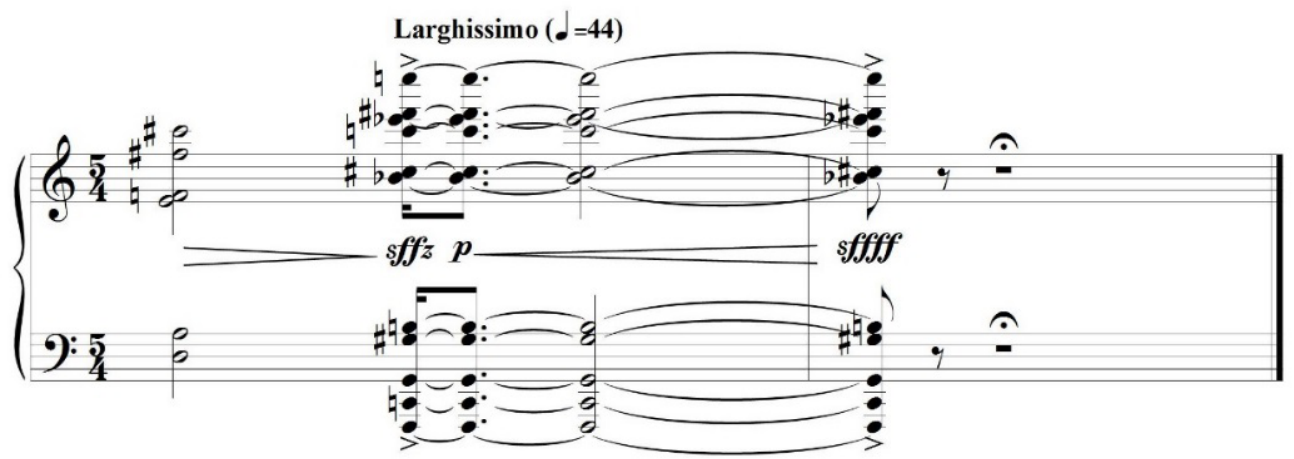

Fig. 7 - Acorde final de Intégrales (1925) de Edgard Varèse. Percussão omitida. Redução (SALLES, 2009, p. 145).

24 Salles (2009) apresenta os termos "cadência wagneriana" e "cadência varèsianas", aqui substituídos pelo termo "finalização", com o intuito de melhorar a compreensão. Diferente da "cadência", a "finalização" não está associada a progressões tonais específicas, como cadências perfeitas, plagais, de engano, a dominante etc. 0 termo está relacionado a procedimentos de encerramento, sejam estes elementos gestuais, texturais, timbrísticos, rítmicos, melódicos etc. 
Segundo Salles, as finalizações "varèsianas" podem ser encontradas em diversas obras de Villa-Lobos, como nos Choros n. 3, n. 7, n. 8 e n. 10, Noneto, Choros Bis, Rudepoema, Bachianas Brasileiras n. 8 (quarto movimento), dentre outras obras (SALLES, 2009, p. 146).

No Lento (Assai) da Sinfonia n. 8, esse procedimento de finalização ocorre de forma similar na abertura do movimento. Villa-Lobos realiza uma sobreposição de notas distribuídas em diversos instrumentos e em vários registros. Este acorde é suspenso através de uma fermata, gerando assim ressonâncias dos intervalos dissonantes e consonantes executados simultaneamente.

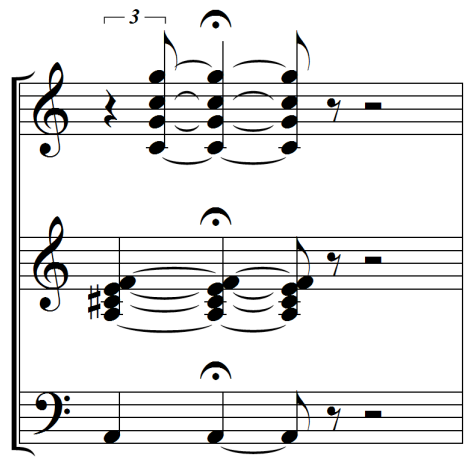

Fig. 8 - Acorde inicial do Lento (Assai) da Sinfonia n. 8 de Heitor Villa-Lobos. Redução. Compasso 2.

\subsubsection{Ciclo de Quintas}

As sequências de tríades ou tétrades em intervalos de quintas são comuns na música barroca. Ocorrendo em grande ou em pequena escala, essas sequências são perceptíveis nas obras de Antonio Vivaldi, Georg Friedrich Händel e Johann Sebastian Bach.

Diether de La Motte menciona que o ouvinte frequentemente não está consciente de que a sequência de quintas está sendo empregada para contrabalançar a tensão harmônica da obra. Após a sequência estabelecida, o ouvinte instintivamente absorve de forma natural essa progressão. Se a sequência é equilibrada juntamente com outros tipos de progressões, ela fornece a sensação de tensão harmônica reduzida. Se a sequência é usada excessivamente, torna-se facilmente banal (MOTTE, 1995, p. 147).

No Lento (Assai) observamos uma alusão à sequência de quintas, também podendo ser chamada de ciclo de quintas. Essa progressão é apresentada pelos primeiros e segundos violinos, e contrabaixos.

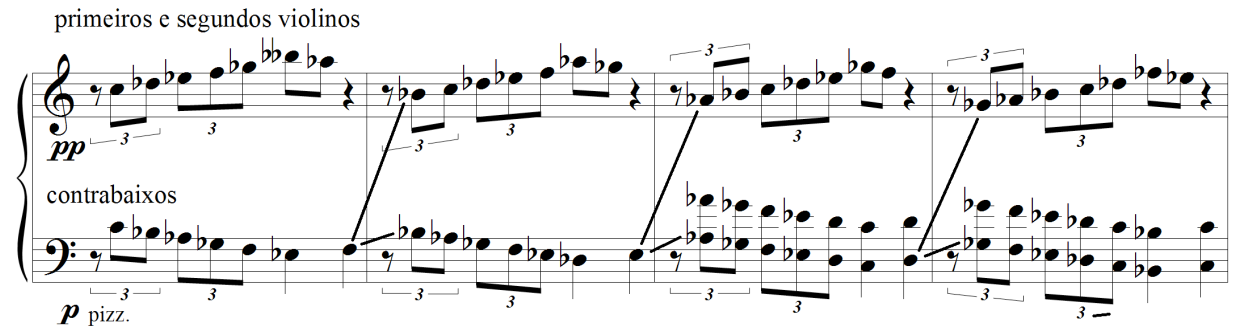

Fig. 9 - Ciclo de quintas. Lento (Assai) da Sinfonia n. 8 de Heitor Villa-Lobos. Redução. Compassos 49-52. 
Na redução da Fig. 10, observamos o gesto musical deste movimento de quintas descendentes com maior clareza. Essa sequência se inicia no $\mathrm{Si}=$ do compasso 50, seguido pelas notas: $M i=$, Lá=, Ré, Sol=, Dó e Fá.

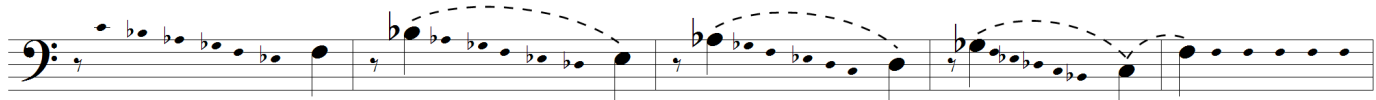

Fig. 10 - Ciclo de quintas. Contrabaixos. Lento (Assai) da Sinfonia n. 8 de Heitor Villa-Lobos. Redução. Compassos 49-53.

Simultaneamente com este pequeno ciclo de quintas, Villa-Lobos insere um ciclo de sextas, executados nos violoncelos, caracterizando um gesto cadencial similar ao do ciclo de quintas, como podemos observar nas Fig. 11 e 12
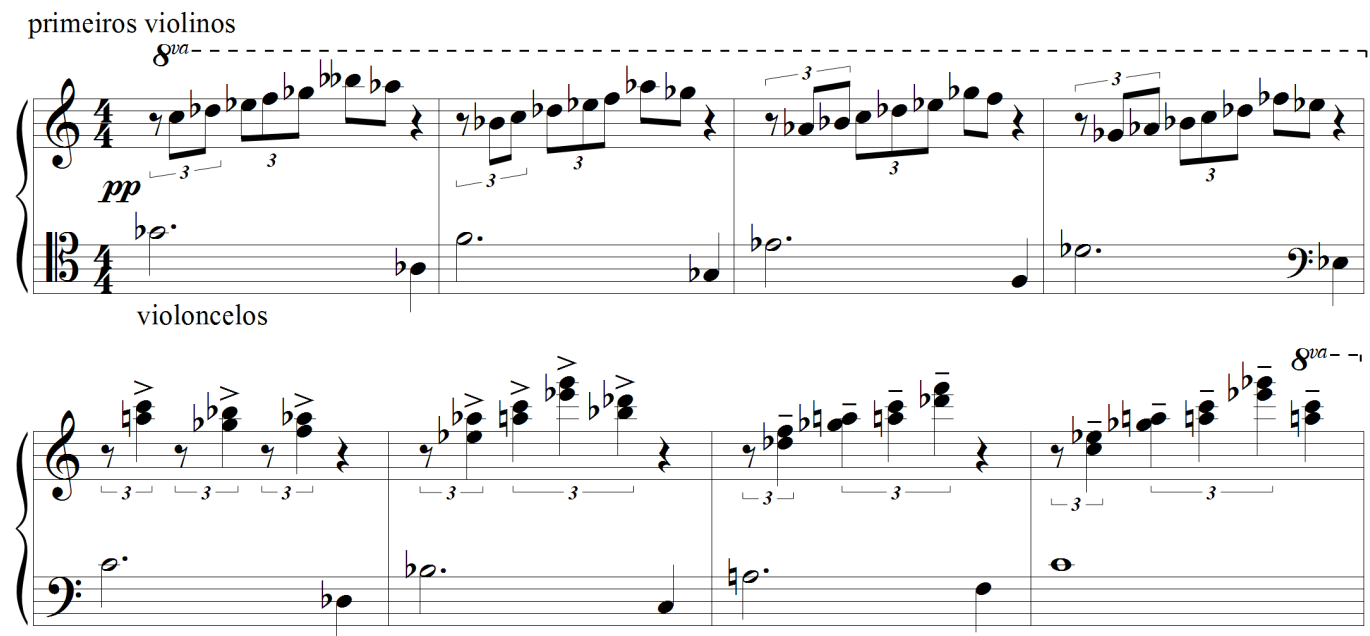

Fig. 11 - Ciclo de sextas. Lento (Assai) da Sinfonia n. 8 de Heitor Villa-Lobos. Redução. Compassos 49-56.
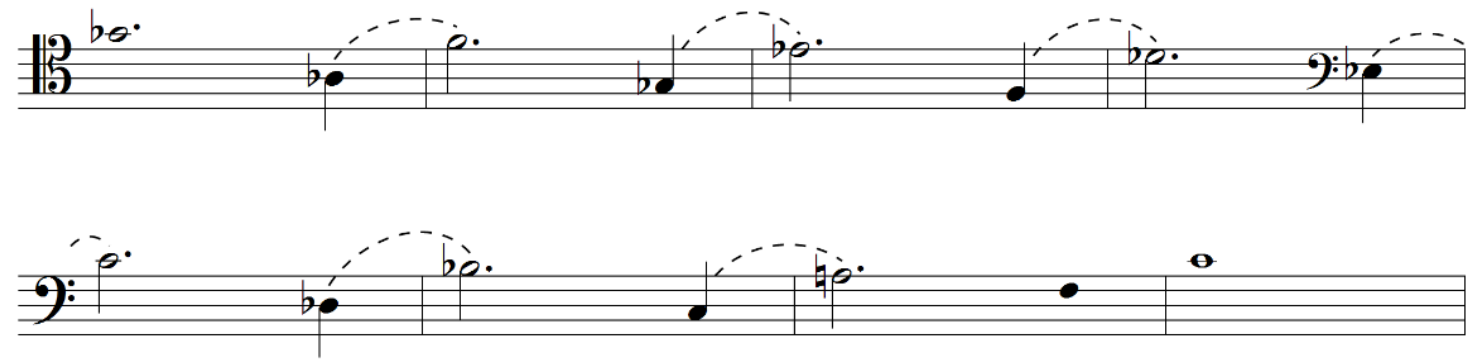

Fig. 12 - Ciclo de sextas. Violoncelos. Lento (Assai) da Sinfonia n. 8 de Heitor Villa-Lobos. Redução. Compassos 49-56.

\subsubsection{Tópica Brejeiro}

A tópica "brejeiro" está associada ao choro e ao jazz brasileiro. Figurações sincopadas, ziguezagues ${ }^{25}$, deslocamento rítmico, cromatismos são algumas características

25 Figurações em dois registros, chamado de "ziguezague". Essas figurações empregadas por Villa-Lobos caracterizam-se por realizar um contorno melódico que estabelece uma espécie de contraponto consigo mesmo, um tipo de polífona interna, onde se tem a impressão de ouvir duas linhas melódicas em um único instrumento. As influências deste tipo de condução melódica podem ter origem da obra de Johann Sebastian Bach, assim como outras fontes de interesse de Villa-Lobos, como figurações melódicas de Callado e Pixinguinha (SALLES, 2009, p. 114-115). 
desta tópica. Segundo Piedade, a tópica "brejeiro" é caracterizada pela forma em que "as figurações aparecem transformadas por subversões, brincadeiras, desafios, exibindo e exigindo audácia e virtuosismo, mas tudo isto de forma organizada, elegante, altiva, por vezes sedutora, maliciosa" (PIEDADE, 2013, p. 12-13).

Na seção B do Lento (Assai) da Sinfonia n. 8, a tópica "brejeiro" é apresentada inicialmente pelo fagote, seguido pelo clarinete e, posteriormente, ornamentada nos primeiros violinos e violas (compasso 30). Na Fig. 11, observamos a melodia em tercinas, executada pelo fagote, sendo acompanhada em terças descendentes pelos clarinetes. Este excerto é caracterizado pela melodia em ziguezague, ilustrada nas Fig. 13 e 14.

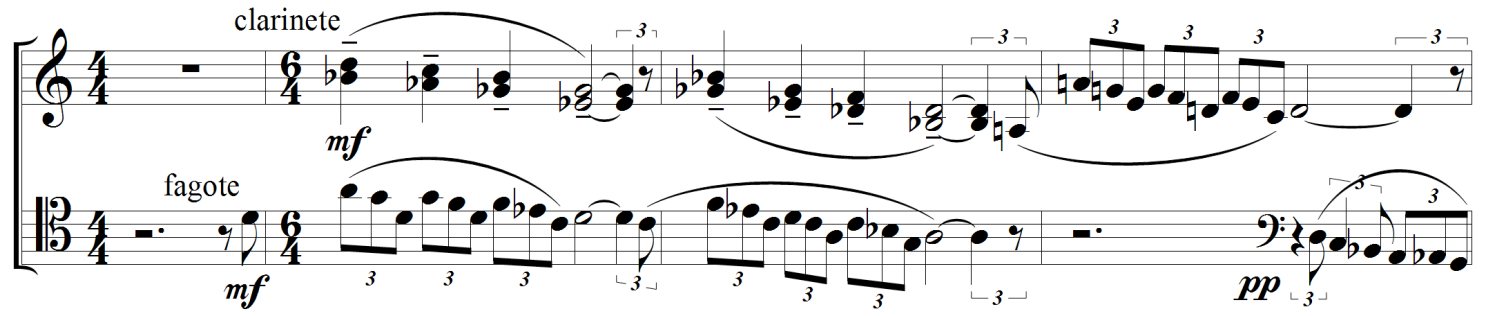

Fig. 13 - Tópica "brejeiro". Lento (Assai) da Sinfonia n. 8 de Heitor Villa-Lobos. Redução. Compassos 18-21.

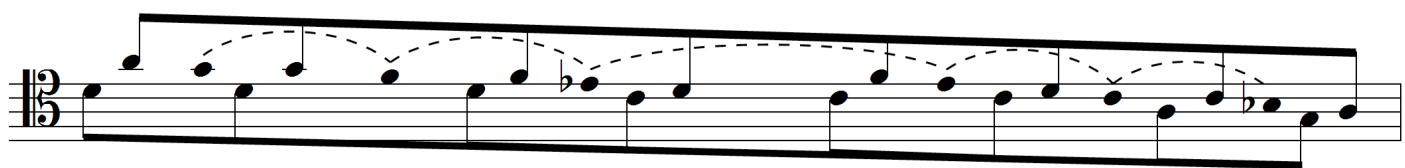

Fig. 14 - Melodia em ziguezague. Tópica "brejeiro". Lento (Assai) da Sinfonia n. 8 de Heitor Villa-Lobos. Redução. Compassos 19-20.

\subsection{Intratextualidade}

Segundo Sant'anna, a intratextualidade ocorre "quando o poeta se reescreve a si mesmo. Ele se apropria de si mesmo, parafrasicamente" (SANT'ANNA, 2007, p. 62). A paráfrase de seu próprio texto é bastante comum em diversos compositores. Elementos como estruturas rítmicas, harmônicas e melódicas são reaproveitadas, sem alterar o sentido original. Villa-Lobos, ao longo de sua vida, cultivou o hábito de reciclar suas obras antigas, dando uma nova roupagem, muitas vezes sob novos títulos. Essa prática de reutilizar material de obras precursoras é comumente aplicada por diversos compositores.

Podemos associar a transição da recapitulação do Lento (Assai) com o gestual do Prelúdio da Bachianas Brasileiras n. 4. Na Fig. 15, observamos os compassos iniciais deste Prelúdio, composto pelo arpejo ascendente de acordes, tendo sua resolução por grau conjunto descendente, sendo acompanhado pelo baixo, executando um ciclo de quintas.

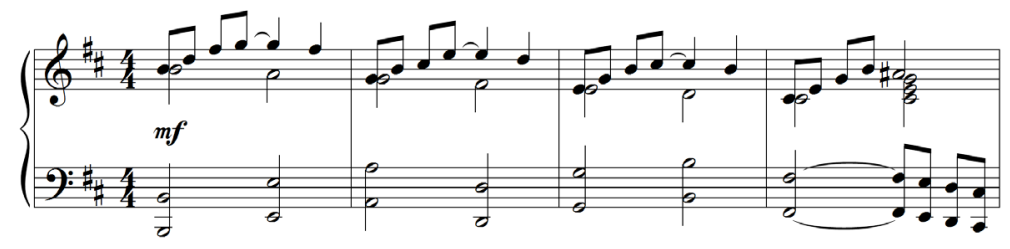

Fig. 15 - Prelúdio da Bachianas Brasileiras n. 4 de Heitor Villa-Lobos. Compassos 1-4. 
Este mesmo gesto é apresentado no Lento (Assai) de forma similar (Fig. 16). Além do já mencionado ciclo de quintas neste excerto, observamos nos primeiros e segundos violinos o arpejo dos acordes de forma análoga, tendo sua resolução por grau conjunto descendente, de forma muito similar ao Prelúdio da Bachianas Brasileiras n. 4, conforme apresentado na figura 17.

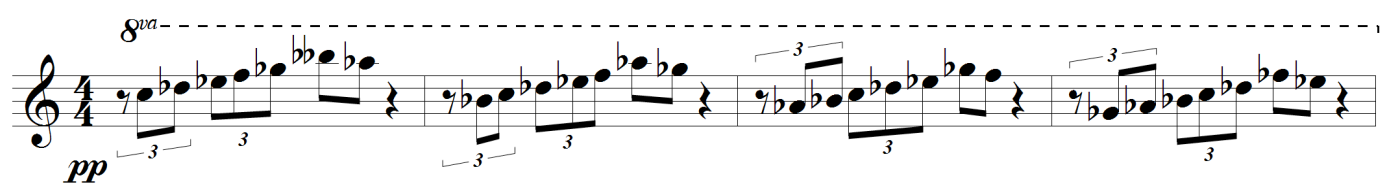

Fig. 16 - Melodia dos primeiros violinos. Lento (Assai) da Sinfonia n. 8 de Heitor Villa-Lobos. Redução. Compassos 49-52.

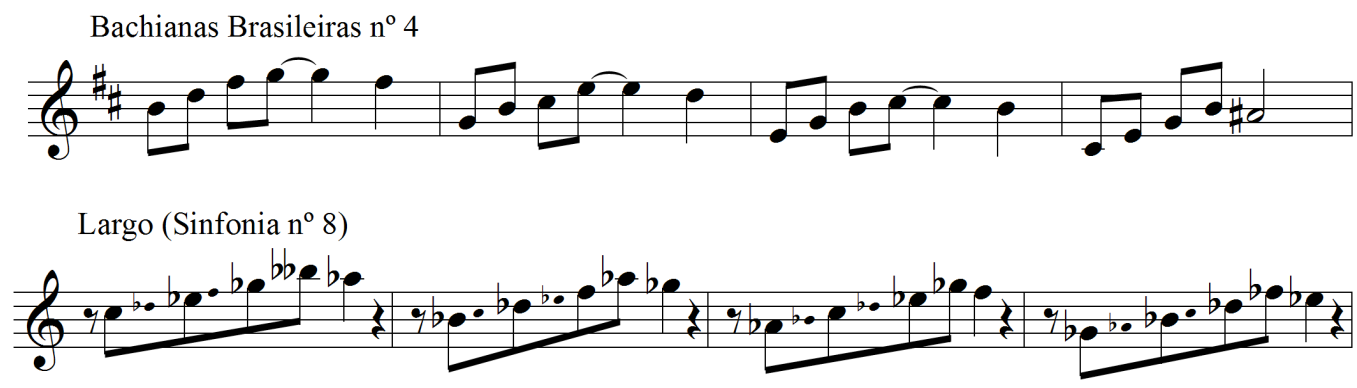

Fig. 17 - Gesto melódico análogo ao Prelúdio da Bachianas Brasileiras n. 4. Lento (Assai) da Sinfonia n. 8 de Heitor Villa-Lobos. Redução.

\section{Considerações finais}

Nas análises aqui apresentadas, constatamos a sobreposição de diversas linguagens presentes no Lento (Assai), segundo movimento da Sinfonia n. 8. Essas linguagens são dispostas através de intertextos com compositores precursores, contemporâneos, elementos originados da música popular brasileira e de intratextos do próprio compositor.

$\mathrm{Na}$ categoria referente às relações intertextuais motívicas, verificamos a possível presença do motivo Tristão no Lento (Assai) da Sinfonia n. 8, análogas ao Prelúdio da ópera de Tristão e Isolda. As finalizações "varèsianas" estão relacionadas à intertextualidade a nível estilístico, apontando as ressonâncias resultantes de diversas dissonâncias agregadas.

O ciclo de quintas é um recurso bastante recorrente na obra villalobiana, em especial em suas obras de caráter tonal, como o ciclo das Bachianas Brasileiras. Mesmo que o ciclo de quintas, presentes no Lento (Assai), não esteja tão aparente (se comparada com o Prelúdio da Bachianas Brasileiras n. 4, por exemplo), auditivamente e gestualmente essa sequência é caracterizada. O gesto melódico do Prelúdio da Bachianas Brasileiras n. 4 também está presente neste movimento, assinalando um intratexto.

No que diz respeito à música popular brasileira, podemos relacionar a melodia da seção B com a tópica "brejeiro".

Através dessa sobreposição de linguagens presentes no Lento (Assai) da Sinfonia $n$. 8, Villa-Lobos apropria-se dos elementos musicais herdados de compositores precur- 
sores e contemporâneos, assim como dos elementos da música popular brasileira, consolidando seu próprio estilo, estando em busca de uma nova música, de uma identidade musical erudita brasileira, instituindo a sua própria idiomática musical.

\section{Referências}

BARBOSA, Lucas de Paula; BARRENECHEA, Lúcia Silva. A intertextualidade musical como fenômeno. Per Musi, Belo Horizonte, v. 8, p. 125-136, 2003.

BLOOM, Harold. A Angústia da Influência: Uma Teoria da Poesia. 2. ed. Tradução Marcos Santarrita. Rio de Janeiro: Imago Ed., 2002.

Um mapa da desleitura. 2. ed. Rio de Janeiro: Imago Ed., 2003.

BURKHOLDER, J. Peter. Intertextuality. Grove Music Online, Oxford University Press. Disponível em: <http://www.oxfordmusiconline.com/subscriber/article/grove/ music/52853>. Acesso em: 9 out. 2015.

CANO, Rúben López. Más allá de la intertextualidad. Tópicos musicales, esquemas narrativos, ironía y cinismo en la hibridación musical de la era global. Nassarre: Revista aragonesa de musicología, La Rioja, v. 21, n. 1, p. 59-76, 2005.

CANO, Rúben López. Música e intertextualitad. Cuadernos de teoria y crítica musical 104, Habana, p. 30-36, 2007.

CASTRO, Daniel Fraga de. A complexidade da angústia da influência de Harold Bloom. XI Semana de Letras. Porto Alegre: 2011. p. 1-14.

COLARUSSO, Osvaldo. Villa-Lobos, um grande sinfonista?. 2013. Disponível em: <http:// www.gazetadopovo.com.br/blogs/falando-de-musica/villa-lobos-um-grandesinfonista/>. Acesso em: 25 jan. 2017.

CROWL, Harry. A Música de Richard Wagner e a sua Influência no Brasil. 2013. Disponível em: <http://blog.goethe.de/wagner/uploads/RichardWagnereoBrasil.pdf>. Acesso em: 25 nov. 2016.

D'INDY, Vincent. Cours de composition musicale, v. 2, n. 1. Paris: Durand e Cie Éditeurs, 1909.

FREITAS, Antônio Carlos Rodrigues de. O desenvolvimento do conceito de intertextualidade. Revista Icarahy, Rio de Janeiro, n. 6, 2011. 
GONTIJO, Marisa Helena Simões. Francisco Braga: uma análise poética e musical de sua canção Virgens mortas, sobre soneto homônimo de Olavo Bilac. Dissertação (Mestrado em Música) - Escola de Música da Universidade Federal de Minas Gerais, Belo Horizonte, 2006.

GUÉRIOS, Paulo Renato. Heitor Villa-Lobos e o ambiente artístico parisiense: convertendo-se em um músico brasileiro. Mana, Rio de Janeiro, v. 9, n. 1, p. 81-108, 2003.

GUÉRIOS, Paulo Renato. Heitor Villa-Lobos: o caminho sinuoso da predestinação. Curitiba: Edição do autor, 2009.

HYDE, Martha M. Neoclassic and Anachronistic Impulses in Twentieth-Century Music. Music Theory Spectrum, California, v. 18, n. 2, p. 200-235, 1996.

KIEFER, Bruno. Villa-Lobos e o Modernismo na Música Brasileira. 2. ed. Porto Alegre: Movimento, 1986.

KLEIN, Michael Lawrence. Intertextuality in Western Art Music. Bloomington and Indianapolis: Indiana University Press, 2005.

KORSYN, Kevin. Toward a new poetics of musical influence. British Jounal-Music Analysis, v. 10, n. 1/2, p. 3-72, 1991.

KRISTEVA, Julia. Introdução à Semanálise. São Paulo: Editora Perspectiva, 1974.

LAGO, Manoel Aranha Corrêa do. O Círculo Veloso-Guerra e Darius Milhaud no Brasil. Rio de Janeiro: RELER Editora, 2010.

MONELLE, Raymond. The Musical Topic: Hunt, Military and Pastoral. Bloomington: Indiana University Press, 2006.

MOTTE, Diether de La. Contrapunto. Barcelona: Editorial Labor, 1995.

MUSEU VILLA-LOBOS. Villa-Lobos: sua obra. Rio de Janeiro: MinC; IBRAM; Museu Villa-Lobos, 2009.

NOGUEIRA, Ilza. A estética intertextual na música contemporânea: considerações estilísticas. Brasiliana, v. 13, p. 2-12, 2003.

PIEDADE, Acácio Tadeu de Camargo. Expressão e sentido na música brasileira: retórica e análise musical. Revista eletrônica de musicologia, Curitiba, v. 11, p. 1-11, 2007.

PIEDADE, Acácio Tadeu de Camargo. Musical topics, intertextuality and rhetoricity in 
Heitor Villa-Lobos Bachianas Brasileiras Nr.2. Topical Encounters and Rhetorics of Identity in Latin American Art Music, Oxford, 2015.

PIEDADE, Acácio Tadeu de Camargo. Tópicas em Villa-Lobos: o excesso bruto e puro. Simpósio Internacional Villa-Lobos, São Paulo, v. 11, p. 127-147, 2009.

RATNER, Leonard Gilbert. Classic Music: Expression, form, and style. New York: Schirmer Books, 1980.

ROSEN, Charles. Influence: Plagiarism and Inspiration. 19th - Century music, California, v. 4, n. 2, p. 87-100, 1980.

SALLES, Paulo de Tarso. O acorde de Tristão em Villa-Lobos. Fórum do Centro de Linguagem Musical, São Paulo, v.1, p. 1-6, 2004.

SALLES, Paulo de Tarso. Villa-Lobos: Processos Composicionais. Campinas: Editora da Unicamp, 2009.

SANT'ANNA, Afonso Romano de. Paródia, paráfrase \& Cia. São Paulo: Ática, 2007.

STRAUS, Joseph Nathan. Remaking the Past: Musical Modernism and the Influence of the Tonal Tradition. Cambridge: Havard University Press, 1990.

TAFFARELLO, Tadeu Moraes. O percurso da intersecção Olivier Messiaen-Almeida Prado: Momentos, La Fauvette des Jardins e Cartas Celestes. Tese (Doutorado em Música) - Universidade Estadual de Campinas, Campinas, 2010. 